\title{
Stress and Depression: A Pre and Post Cochlear Implant Comparative Study
}

\author{
Teja Deepak Dessai ${ }^{1 *}$ and DeepikaKramadhari ${ }^{2}$ \\ ${ }^{1}$ Lecturer, Nitte Institute of Speech and Hearing, India \\ ${ }^{2}$ Undergraduate student, Nitte Institute of Speech and Hearing, India
}

Submission: March 04, 2016; Published: March 10, 2017

*Corresponding author: Teja Deepak Dessai, Lecturer, Nitte Institute of Speech and Hearing, Nithyananda Nagara, Derelakatte, Mangalore, Dakshina Kannada, India, Tel: +91 824220 4069; Email: dessaiteja@gmail.com

\begin{abstract}
Parents of children with hearing impairment tend to exhibit "depression" a known stress related response. Mothers of hearing impaired child are more prone than fathers to experience depression [1,2]. In addition, these mothers are found to be less successful in cultivating language and psychological development of their children. The study aimed to measure pre and post cochlear implantation (CI) levels of maternal stress and depression. Total of 5 mothers were supplied with Parental Stress Scale (PSS) and Centre for Epidemiologic studies Depression Scale (CESD) adapted in Kannada Language pre and post CI of their children. Wilcoxon Signed Ranks test was applied to the obtained data.No significant difference in mean levels of stress and depression pre and post $\mathrm{CI}(\mathrm{p}<0.05)$ was observed. The results provide preliminary evidence that mothers of children with hearing impairment experience higher levels of stress and depression.
\end{abstract}

Keywords: Cochlear implant; Stress; Depression

\section{Introduction}

Parents dream their child to share and enjoy access to the full array of life options. Hearing impairment is an invisible handicap. Parents, giving birth to hearing impaired child are unaware of the child's hearing impairment. Hearing impairment if not identified and rehabilitated/habilitated in the early days of life, can hamper the speech, language and communication abilities of a child in comparison to a hearing peer group. Labelling the child with hearing impairment leads to an emotional catastrophe in the life of parents. Most common reactions by parent to the labelled diagnosis include guilt and anger, helplessness, feeling of grief, a sense of isolation in parent-child relation with central role to human communication [3].

A series of emotional stages mount upon labelling their child with hearing impairment. Literature reports three main stages in parental response. (a) Premature expression of anger towards the professional who labelled the child with hearing impairment. (b) Succeeding expression of anger on their child as they find it hard to deny the continued existence of hearing impairment. (c) Alteration of emotions from sadness \& anger to progress of adaptation and coping behaviours in accepting the hearing impaired child [4]. Altering degrees of grief, anger and worry are associated with adjustment of the child with disability
[5]. The task of parenting becomes challenging when the option of amplification is introduced to the hearing impaired child. Today, more technological options are availed to the children with profound hearing loss, thereby, having an access to better speech and language development skills. Cochlear implants have gained its importance in children with severe to profound hearing loss [6].

The gradual increase in use of cochlear implants has developed a curiosity in the researchers to know the superiority of cochlear implant over other amplification devices. Maternal stress and depression is researched upon as it is considered as a factor towards rehabilitation of hearing impaired children.

\section{Need for the study}

Successful declaration of parental anger and grief at labelling of child is crucial, as these emotions may manifest as depression. Childs outcome in all modalities can be negatively affected due to depression. Mothers with depression are found to be less sensitive to their child's needs, nurturing language and psycho-social development. Mothers of children with disability experience more stress associated to parenting in comparison to parents with children without disabilities [7]. Children with hearing impairment are more susceptible to the impact of 
maternal depression as they specifically rely on the maternal care and emotional responsiveness [8]. Positive self esteem of the parents especially the mother plays a key role in the child's success and thus clinical endeavours should emphasise on building the parents self confidence and self esteem [9].

Better developed emotional sensitivity, reading competence, and problem-solving behaviour of the child is observed when mothers with hearing impaired children acquire strategies to cope up with hearing impairment of the child [10]. There has been a positive influence of the language development of hearing impaired child when particularly mothers showed a positive emotional feeling. Hence, there becomes a need to carry out a study revealing the contribution of maternal expectations and related stress and depression pre and post $\mathrm{CI}$ of the hearing impaired child.

A. Aim: To measure and compare pre and post CI maternal stress and depression levels.

\section{B. Method:}

a) Participants: A total of 5 mothers of hearing impaired children (severe to profound hearing loss) within age range of 20-35years were recruited for the study. This study was carried out in Speech and Hearing Institute, Mangalore where the children of these mothers attended regular invention program. The inclusion criteria formed of children bearing severe to profound hearing loss in the age range of 3-7years. Mothers with minimum educational qualification of 10th grade and surviving with the socio-economic status of monthly income less than 8000/-.

b) Materials: Two standardised Parental Stress Scale (PSS) \& Centre for Epidemiologic studies Depression Scale (CESD) self reporting scales were used. These scales were also adapted in Kannada Language (a south Indian Dravidian language Results \& Discussion spoken in the state of Karnataka) and were implemented in the study.

Parental stress Scale [11] is 18-item self report scale designed to evaluate the stress in the parents. It attempts to measure the levels of stress a parent experiences and also centres on positive and negative aspects of parenting. It is a 5-point scale (strongly disagree, disagree, undecided, agree, and strongly agree) with positive items e.g. emotional benefits, personal development and negative items e.g. demands on resources, restrictions of parenthood. This self rating scale asses changes in parental stress levels for parents/carers who have accessed targeted support, such as family support, parenting course, one to one parenting support and the outcomes of services or areas of work focused on improving parents/carers parenting capacity.

This scale is relatively easy to administer and takes approximately 10 minutes. Higher levels of stress relate to the low levels of parental sensitivity to the child, poor parent child relationship and poor child behaviour. Centre for Epidemiologic studies Depression Scale [12] is a 20 item scale designed to measure and assess the levels of depressive symptoms and mood in general population. It is 4 point rating scale ( $1=$ rarely or none of the time and $4=$ Most or all of the time).

\section{Procedure}

An oral consent was taken from all the mothers who participated in the study. The self rating scales of stress and depression were provided to the mothers' pre and post CI of their child. Post CI included time duration of 1 month after surgery. Incompletely furnished scales and questionnaires were discarded. The collected data was recruited to the statistical analysis. In addition, to obtain a significant difference between the pre and post CI stress and depression levels in mothers, Wilcoxon Signed Ranks test was applied.

Table 1: Mean, standard deviation and $\mathrm{Z}$ value for the stress and depression experienced by the mothers of $\mathrm{Cl}$ child.

\begin{tabular}{|c|c|c|c|}
\hline Variable & Mean & Group & SD \\
\hline \multirow{2}{*}{$\begin{array}{c}\text { Life stress Pre CI } \\
\text { Life stress Post CI }\end{array}$} & 56.2 & \multirow{2}{*}{5 subjects } & 8.04 \\
\cline { 2 - 3 } $\begin{array}{c}\text { Depression Pre CI } \\
\text { Depression Post CI }\end{array}$ & 54 & & 8.68 \\
\cline { 2 - 4 } & 28.4 & & 15.1 \\
\end{tabular}

The data obtained using PSS and CESD underwent statistical analysis. The obtained results are mentioned below. There was no significant difference in levels of stress and depression pre and post CI $(\mathrm{p}<0.05)$ on the mean scores (Table 1). Stress and depression among the parents of children with CI is not inevitable. It moulds the family system. The current study results revealed higher levels of stress and depression pre CI in comparison to post CI. However, the scores obtained did not show any significant difference between pre and post CI.
A cochlear implant provides the subject an access to hear various sounds which he/her may not have heard [13]. Lesser levels of stress and depression indicate better performance of cochlear implant users and it can be associated to their mothers. This can be attributed to the findings of Francis, Koch, Wyatt and Niparko [14] which revealed, higher performance in children using cochlear implant in comparison to the hearing aid users. . Mothers of children with severe to profound hearing loss tend to exhibit higher levels of stress and depression, anger and anxiety in comparison to the mothers of normal hearing children 
[15]. The no significant difference in the levels of stress and depression on choosing cochlear implant can be related to the feeling of being taxed which might occupy most of their time. This finding is supported by Sima and Seyed [16].

Parents with hearing impaired children are put up with pressures associated with everyday difficulties incorporating verbal communication and educational problems, costs of rehabilitation of CI. This together with problems faced by children in society increases parental stress. Similarly, lower socioeconomic status of the family requires family support and adjustment to the financial constraints in the family [10]. The mothers would have undergone related stress levels in coping with isolation, depression and family support. Moreover, the financial constraints on maintenance of the cochlear implant, the device used pre CI and the ongoing rehabilitation program would have imposed several maternal expectations under the influence of stress and depression.

The current study imposed on highlighting the psychological aspects of mothers who have to be considered by the rehabilitative specialist of the child. The presence of higher levels of maternal stress and depression may hinder the parent child relation and in turn impact developmental and educational outcomes of the child. The study highlights the need to start the family based intervention program to boost the parents with children having HI. Similarly, stress and depression may alter the quality of life of the mother as well as the child. Hence, it is the responsibility of the Audiologist and Speech Language Pathologist to build up self esteem and confidence of the parents with HI children.

\section{Conclusion}

The current study measured and compared maternal expectations, stress and depression in mothers with children with CI. Findings of the study did not show significant difference in levels of stress and depression pre and post CI. However, the considered subject size was relatively small and other family members levels of stress and depression have not been considered. Thus, it calls for the next research to incooperate large subject group comprising of various subjects related the hearing impaired child.

\section{References}

1. Mavrolas C (1990) Attachment behavior of hearing impaired infants and their hearing mothers: Maternal and infant contributions.
Unpublished doctoral dissertation, North Western University, Evanston, IL.

2. Meadow-Orleans K (1995) Sources of stress for mothers and fathers of deaf and hard of hearing infants. Am Ann Deaf 140(4): 352-357.

3. Nancy K, Mellon MS (2009) Parental Response to the Diagnosis of Hearing loss. In Niparko JK (Eds) in Cochlear Implants: principles \& practices.

4. Stein LK, Jabaley T (1981) Behavioral Hearing Testing of Children. In Northern, J.L. \& Downs, M.P. (4 ${ }^{\text {th }}$ ed): Hearing In Children. William \& Wilkins. New York, USA, pp. 183.

5. McDowell RL (1976) Parent Counseling: The state of the art. Journal of learning disabilities 9(10): 614-619.

6. Spencer P, Marschark M (2003) Cochlear Implants: Issues and Implications in M. Marschark (ed). Oxford handbook of deaf studies, language, and education. Oxford University Press, New York, USA, pp. 434-448

7. Orlans KPM, Spencer PE, Sanford L (2004) Hearing Parents' Reactions to the Identification of Deafness and Cognitive or Motor Disabilities. In The world of deaf infants: a longitudinal study, 66, Oxford University Press, UK.

8. Beardslee WR, Bemporad J, Keller MB, Klerman GL (1983) Children of parents with major affective disorder: A review. Am J Psychiatry 14(7): 825-832.

9. Luterman DM (1999) The young deaf child. MD: York Press, Inc, Baltimore, USA.

10. Punch R, Hyde M (2010) Rehabilitation efforts \& stress in parents of children with cochlear implant. The Australian and New Zealand Journal of Audiology 32(1): 1-18.

11. Judy O Berry, Warren H Jones (1995) The Parental Stress scale: Initial psychometric evidence. Journal of Social and Personal Relationships 12: 463-472.

12. Radloff LS (1977) The CES-D Scale: A self-report depression scale for research in the general population. Applied Psychological Measurement (1): 385-401.

13. Donna, L. S., \&Caleffe-Schenck, N. (2008) Cochlear Implant Rehabilitation. 13059 E. Peakview Avenue Centennial, Co 80111 USA.

14. Francis HW, Koch ME, Wyatt JR, Niparko JK (1999) Trends in educational placement and cost-benefit considerations in children with Cochlear Implants. Arch Otolaryngol Head Neck Surg 125(5): 499-505.

15. Quittner AL (1991) Coping with a hearing-impaired child: A model of adjustment to chronic stress. In JH Johnson and SB Johnson (eds.), Advances in child health psychology, Gainesville, FL: University of Florida Press, pp.206-223.

16. Sima F, Seyed MK (2013) Depression, Anxiety, and Stress among Mothers of Healthy Children and Mothers of Children with Cochlear Implants. Journal of Social Issues \& Humanities 1(5): 2345-2633.
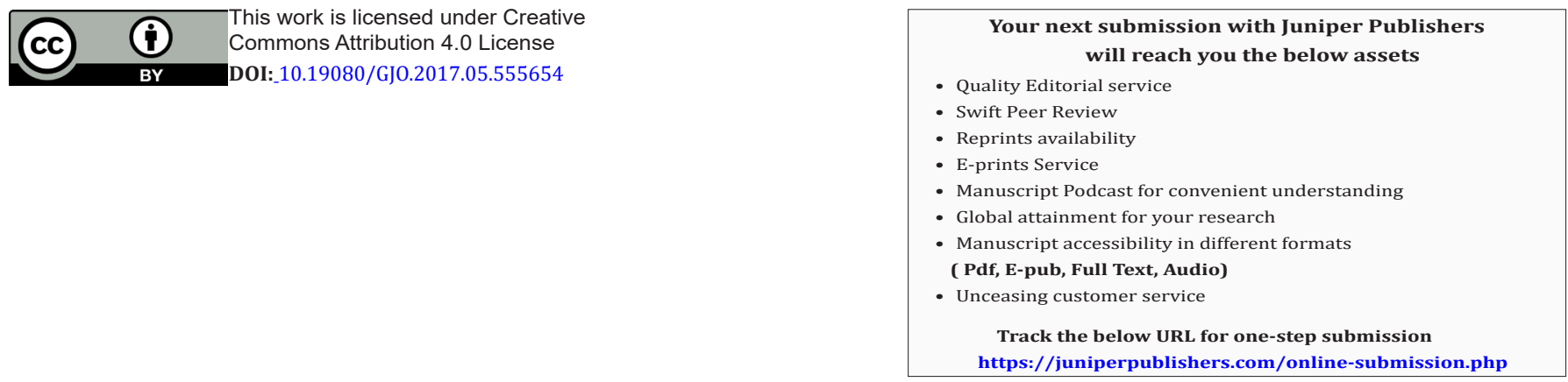